\title{
Research Article \\ Direct Oxidation Growth of CuO Nanowires from Copper-Containing Substrates
}

\author{
Benjamin J. Hansen, Ganhua Lu, and Junhong Chen \\ Department of Mechanical Engineering, University of Wisconsin-Milwaukee, Milwaukee, WI 53211, USA
}

Correspondence should be addressed to Junhong Chen, jhchen@uwm.edu

Received 20 September 2007; Accepted 3 January 2008

Recommended by Junlan Wang

Controlling the growth of semiconducting nanowires with desired properties on a reproducible basis is of particular importance in realizing the next-generation electronic and optoelectronic devices. Here, we investigate the growth of cupric oxide (CuO) nanowires by direct oxidation of copper-containing substrates at $500^{\circ} \mathrm{C}$ for 150 minutes at various oxygen partial pressures. The substrates considered include a low-purity copper gasket, a high-purity copper foil, compacted $\mathrm{CuO}$ and $\mathrm{Cu}_{2} \mathrm{O}$ thin layers, and layered $\mathrm{Cu} / \mathrm{CuO}$ and $\mathrm{Cu} / \mathrm{Cu}_{2} \mathrm{O}$ substrates. The morphology, composition, and structure of the product $\mathrm{CuO}$ nanowires were analyzed using scanning electron microscopy, energy-dispersive X-ray spectroscopy, transmission electron microscopy, selected area electron diffraction, X-ray diffraction, and UV-Visible absorption. Selected oxidation processes have been monitored using a thermogravimetric analyzer. The layering structure of the substrate after oxidation was analyzed to elucidate the growth mechanism of $\mathrm{CuO}$ nanowires.

Copyright (c) 2008 Benjamin J. Hansen et al. This is an open access article distributed under the Creative Commons Attribution License, which permits unrestricted use, distribution, and reproduction in any medium, provided the original work is properly cited.

\section{INTRODUCTION}

One-dimensional nanostructures that can efficiently transport electrical carriers have been an exciting area of research due to their potential applications in next-generation optoelectronic [1], electronic [1], bio- [2], and gas- [3] sensing devices. Research in the controlled growth of semiconducting nanowires (NWs) is of particular importance in achieving the desired properties on a reproducible basis. Various growth techniques have been employed, including the vapor-liquid-solid growth [4], epitaxial growth [5], vaporsolid growth [6], wet chemical methods [7], and electrospinning [8]. For vapor-solid growth, it has been known since the 1950s that the oxidation of various metals, including copper, iron, zinc, and tantalum, at intermediate temperatures, results in a parallel oxide layering with high-density oxide wires/whiskers at the surface [9]. However, only recently with the advent of advanced characterization and assembly techniques has this phenomenon revived interest. The simplicity of the vapor-solid technique, together with its high NW yield and potential for controllability, makes it an attractive avenue for NW growth.
Cupric oxide $(\mathrm{CuO})$ has been extensively studied due to its application in high Tc superconductors [10] and as a heterogeneous catalyst [11]. In addition, bulk $\mathrm{CuO}$ with a known band gap of $1.2 \mathrm{eV}$ has an interesting monoclinic crystal structure belonging to the Mott insulator material class whose electronic structure cannot be described by conventional band theory [12]. CuO NW arrays have been recently applied to various applications including gas sensing [3], field emission [13, 14], and photovoltaic devices [7]. The vapor-solid oxidation technique has been widely used to grow $\mathrm{CuO}$ NWs $[6,14-17]$ from copper substrates. Recent studies on $\mathrm{CuO}$ NWs have focused on the influence of temperature, growth time, and oxidative environment on the growth rate, size distribution, and areal density of $\mathrm{CuO}$ nanowires $[6,14,15]$. It has been shown that the growth time can be used to control NW length distribution, the growth temperature can be used to control the NW diameter distribution [6], and the $\mathrm{O}_{2}$ and $\mathrm{H}_{2} \mathrm{O}$ partial pressures strongly affect the NW areal density $[15,16]$. The surface condition of the copper substrate was also shown to significantly affect the nanowire growth [17]. 


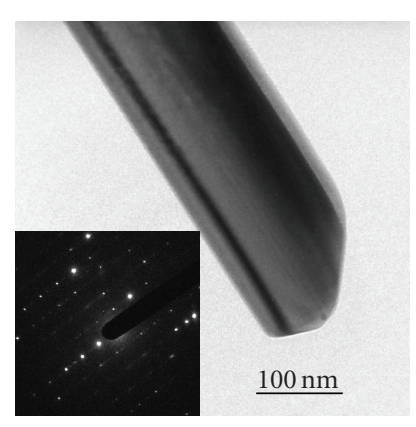

(a)

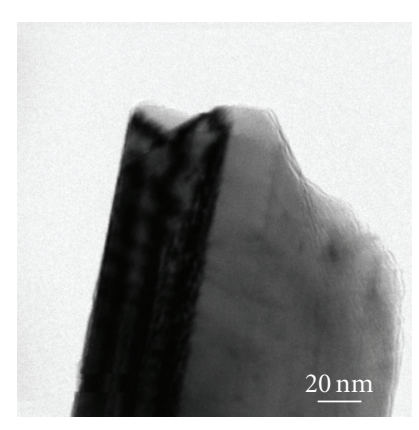

(c)

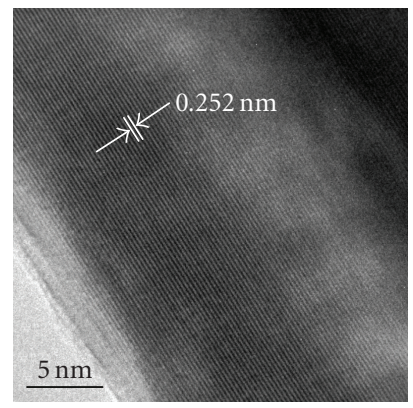

(b)

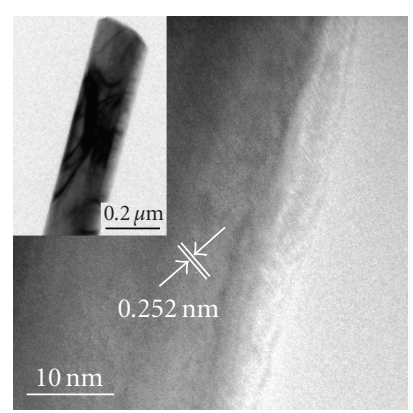

(d)

FIGURE 1: Bright field TEM (a) and HRTEM (b) images of a nanowire grown from a high-purity Cu foil with the inset of (a) being a SAED pattern; (c) BF TEM image of a nanowire grown from a low-purity Cu gasket; and (d) HRTEM image of a nanowire (the inset) shows fringes that are not parallel to the nanowire axis.

A common problem with the vapor-solid oxidation growth of $\mathrm{CuO}$ NWs from copper substrates is that the mismatching stress between the substrate and the oxide layer leads to the flaking of the oxide layer and hence the poor electrical contact between the NW and the substrate. Herein, we investigate the growth of $\mathrm{CuO} \mathrm{NW}$ directly from coppercontaining substrates, such as $\mathrm{CuO}$ and $\mathrm{Cu}_{2} \mathrm{O}$ layers with and without a $\mathrm{Cu}$ substrate. In addition, the effect of $\mathrm{O}_{2}$ partial pressure on NW areal density is investigated. The layering of the substrate after oxidation is analyzed to elucidate the growth mechanism. The resulting $\mathrm{CuO}$ NWs on a conducting/semiconducting substrate can be directly used for electronic applications.

\section{EXPERIMENTAL DETAILS}

Both copper substrates and copper-containing substrates were used for the growth of $\mathrm{CuO}$ NWs. Copper substrates used include a low-purity $\mathrm{Cu}$ gasket with high surface roughness and a high-purity $\mathrm{Cu}$ foil (5Ns, $0.2 \mathrm{~mm}$ thick) with low surface roughness. Before the NW growth, the $\mathrm{Cu}$ substrates were cleaned in $1 \mathrm{M} \mathrm{HCl}$ solution for $\sim 30$ seconds, then rinsed in deionized water, and finally dried in a dry airflow. Copper-containing substrates used include $\mathrm{CuO}$ and $\mathrm{Cu}_{2} \mathrm{O}$ thin layers that were created by compacting commercial $\mathrm{CuO}(3 \mathrm{Ns},<74 \mu \mathrm{m})$ and $\mathrm{Cu}_{2} \mathrm{O}(2 \mathrm{Ns},<74 \mu \mathrm{m})$ powders under $103 \mathrm{MPa}$ for $\sim 2$ minutes. Likewise, $\mathrm{CuO}$ and $\mathrm{Cu}_{2} \mathrm{O}$ powders were deposited onto high-purity $\mathrm{Cu}$ foils and compacted to create $\mathrm{Cu} / \mathrm{CuO}$ and $\mathrm{Cu} / \mathrm{Cu}_{2} \mathrm{O}$ layered substrates.
$\mathrm{CuO}$ NWs were grown by direct oxidation of the above substrates in pure $\mathrm{O}_{2}$ or $\mathrm{Ar}-\mathrm{O}_{2}$ mixtures. The oxidation processes were normally carried out inside a Lindberg/Blue Mini-Mite tube furnace. However, to monitor the oxidation process, a few substrates were oxidized using a TA Instrument SDT 2960 horizontal thermogravimetric analyzer (TGA). During a typical oxidation procedure, a substrate was exposed to an $\mathrm{Ar}-\mathrm{O}_{2}$ gas mixture of $5 \mathrm{lpm}$ with the desired $\mathrm{O}_{2}$ partial pressure, then heated at $\sim 50^{\circ} \mathrm{C} / \mathrm{min}$ to an isotherm of $500^{\circ} \mathrm{C}$ and held for 150 minutes. Upon cooling down, a pure inert gas flow was introduced to prevent the further oxidation. The $\mathrm{O}_{2}$ partial pressures were controlled at $10 \%, 15 \%, 20 \%$, and $100 \%$ (pure $\mathrm{O}_{2}$ ) by mixing $\mathrm{O}_{2}$ with $\mathrm{Ar}$ at appropriate flow rates using mass flow controllers.

Following the oxidation process, each sample was analyzed using a Topcon ABT-32 scanning electron microscope (SEM) equipped with an energy dispersive X-ray (EDX) spectrometer. SEM images were used to analyze the NW morphology and oxide layering and the EDX was used to determine the elemental composition of the sample. The asproduced NW samples were first scratched off their growing substrates, and then transferred onto copper grids and analyzed using a Hitachi H 9000 NAR transmission electron microscope (TEM) for bright field (BF) TEM and highresolution TEM (HRTEM) imaging and selected area electron diffraction (SAED). A Scintag XDS 2000 X-ray diffractometer (XRD) was used for further analyzing the crystal structure of the samples. An Ocean Optics 2000 UV-Visible spectrometer was used to obtain the absorption spectrum 


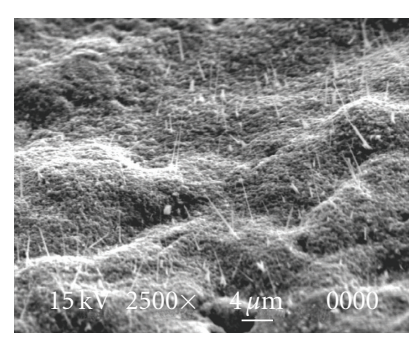

(a)

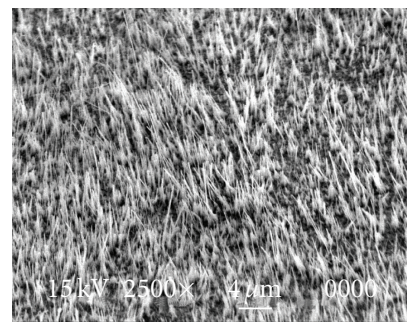

(c)

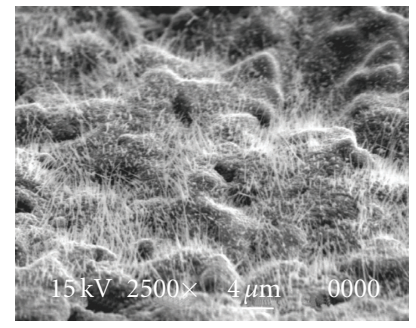

(b)

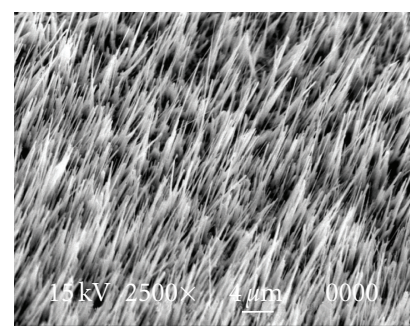

(d)

FIGURE 2: SEM images of oxidized copper substrates at various $\mathrm{O}_{2}$ partial pressures: (a) 10\%, (b) 15\%, (c) 20\%, and (d) $100 \%$.

(reflection mode) of an as-grown high-density NW array. The reflection from a high-quality mirror was used as the reference.

\section{RESULTS AND DISCUSSION}

Figures 1(a) and 1(c) show low-magnification TEM images of nanowires grown in pure $\mathrm{O}_{2}$ from a high-purity $\mathrm{Cu}$ foil and a low-purity $\mathrm{Cu}$ gasket, respectively. The corresponding HRTEM images of the NWs are shown in Figures $1(\mathrm{~b})$ and $1(\mathrm{~d})$, respectively. The visible stripes identified with different contrasts in Figures 1(a) and 1(c) indicate that as-grown nanonwires bear faceted instead of circular cross-sections. The SAED pattern of the NW in the inset of Figure 1(a) confirms the crystallinity of product nanowires and the direction of diffraction spots is consistent with the fringe direction shown in the HRTEM image of Figure 1(b). The lattice spacing of the NWs was measured as $0.252 \mathrm{~nm}$, corresponding to the (111) plane of $\mathrm{CuO}$. The direction of the fringes in Figure 1(b) is in parallel with the nanowire axis, while the fringes shown in Figure 1(d) are not parallel to the wire axis, with a similar angle of $50^{\circ}$ reported in [9]. The two observed fringe directions may be attributed to the difference in surface orientation or surface roughness of the corresponding substrates $[18,19]$. The direction in which a crystal grows on a substrate is dependent on the orientation of the seed crystal. As $\mathrm{CuO}$ NWs grow from a $\mathrm{Cu}$ foil, which is polycrystalline and consists of grains with varying crystallographic orientations, their growth directions would be different from each other, leading to dissimilar fringes of the NWs in HRTEM images.

The low-purity copper substrates were oxidized at four different $\mathrm{O}_{2}$ partial pressures of $10 \%, 15 \%, 20 \%$, and $100 \%$. Upon inspection after oxidation, the surfaces of the

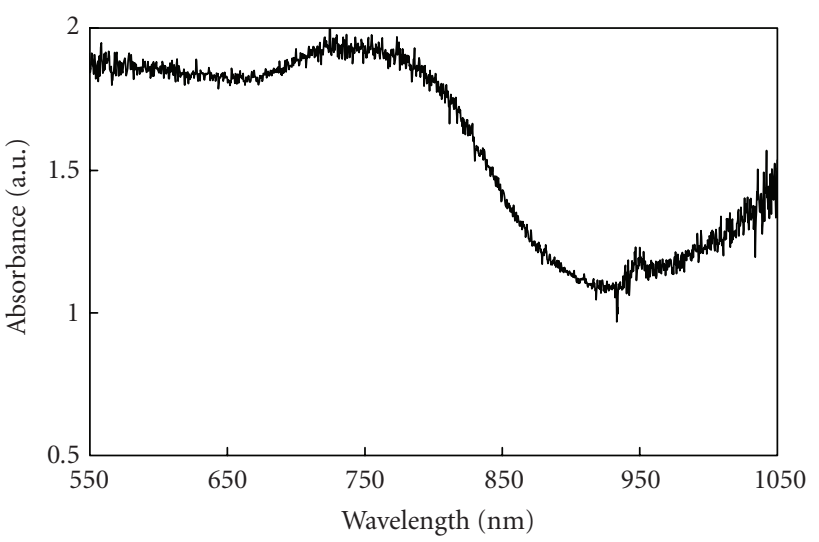

FIGURE 3: UV-Visible absorption spectrum of a $\mathrm{CuO}$ nanowire array.

copper substrates were tarnished from light to dark grey with respect to the $10 \%$ to $20 \% \mathrm{O}_{2}$ partial pressures, whereas the substrate oxidized in $100 \% \mathrm{O}_{2}$ was tarnished almost completely black with only several small grey areas. The SEM images of the oxidized copper substrates are shown in Figures $2(a)-2(d)$. Since the NW density varies throughout the surface of each individual substrate, the images shown are those representative areas with more uniformly dense NWs on each substrate. The NW density and the vertical alignment increase with increasing $\mathrm{O}_{2}$ partial pressures, while the average length and diameter of the NWs seem to decrease with decreasing $\mathrm{O}_{2}$ partial pressures. Most NWs appear to be tapered like a needle or whisker, which may be due to the high roughness of the substrate and the subsequent merging of multiple NWs into one NW during the growth. In the case of pure $\mathrm{O}_{2}$, the areas of highest NW 


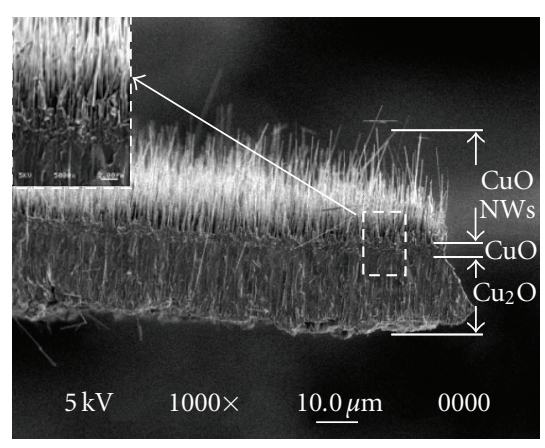

(a)

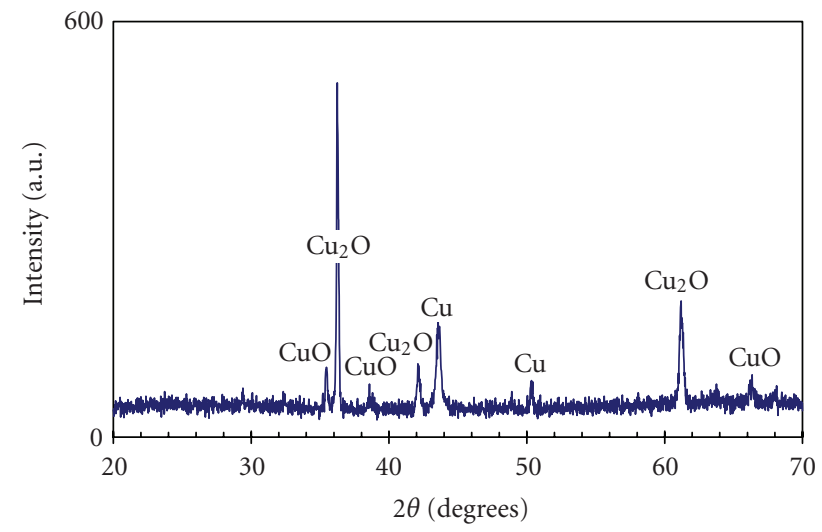

(b)

FIGURE 4: (a) SEM images and (b) XRD spectrum of an oxidized copper substrate.

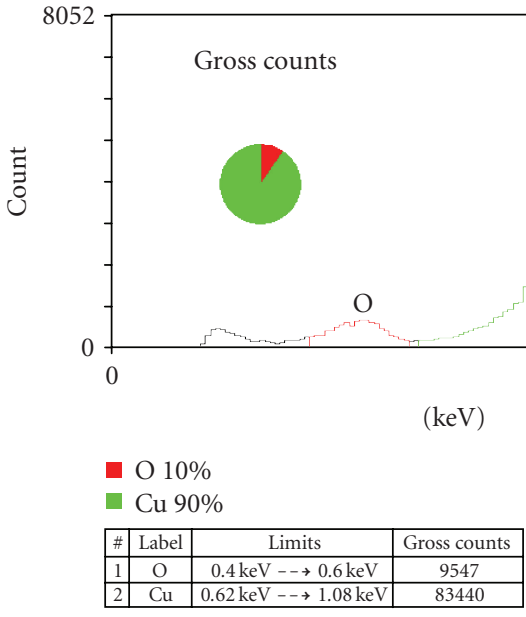

(a)

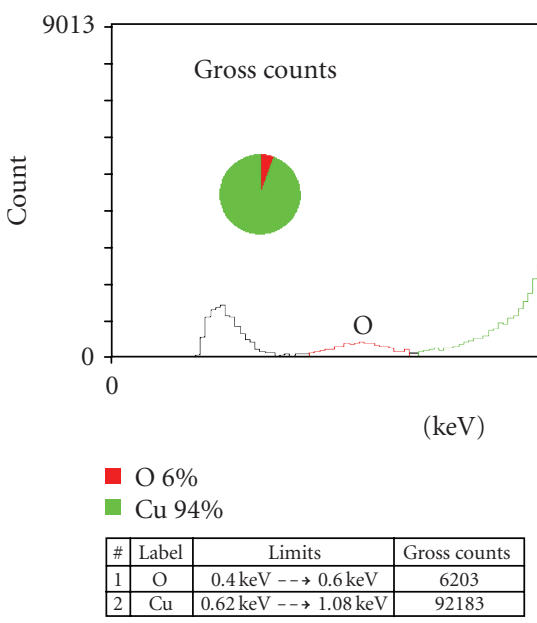

(c)

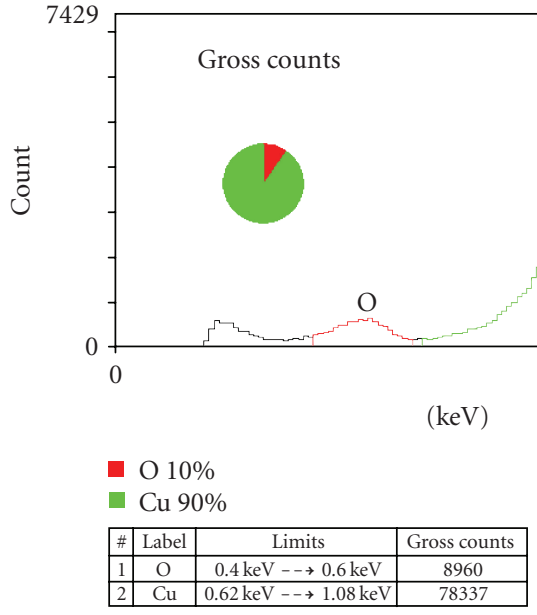

(b)

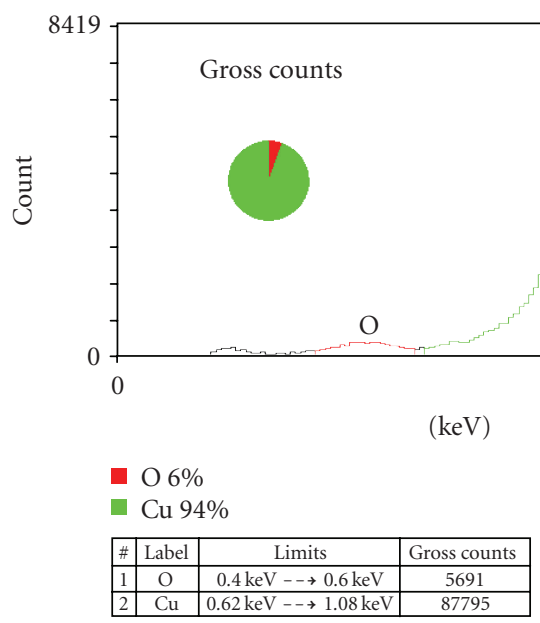

(d)

FIGURE 5: EDX spectra and region analysis: (a) CuO standard; (b) top of the oxide flake; (c) $\mathrm{Cu}_{2} \mathrm{O}$ standard; and (d) bottom of the oxide flake. 


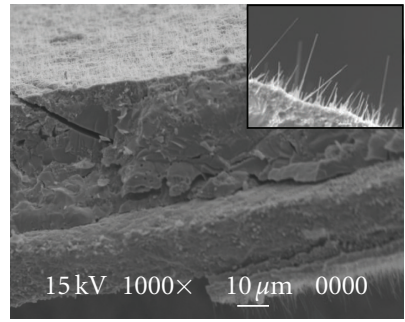

(a)

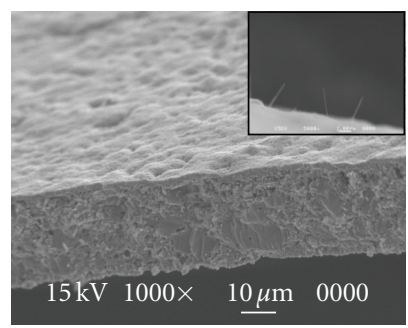

(c)

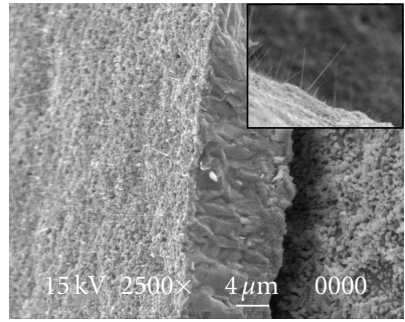

(b)

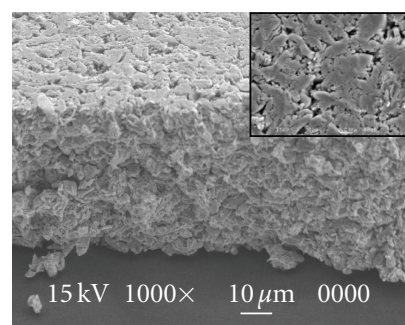

(d)

FIgure 6: SEM images of the substrates after oxidation: (a) $\mathrm{Cu} / \mathrm{Cu}_{2} \mathrm{O}$, (b) $\mathrm{Cu} / \mathrm{CuO}$, (c) $\mathrm{Cu}_{2} \mathrm{O}$ thin layer, and (d) $\mathrm{CuO}$ thin layer. The insets show the amplified top surface details of the corresponding substrates.

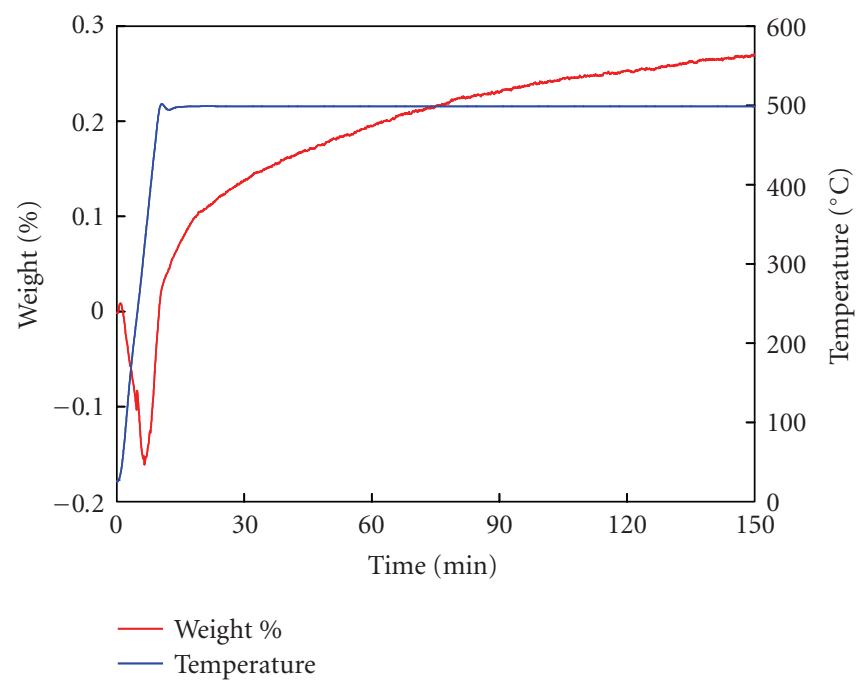

(a)

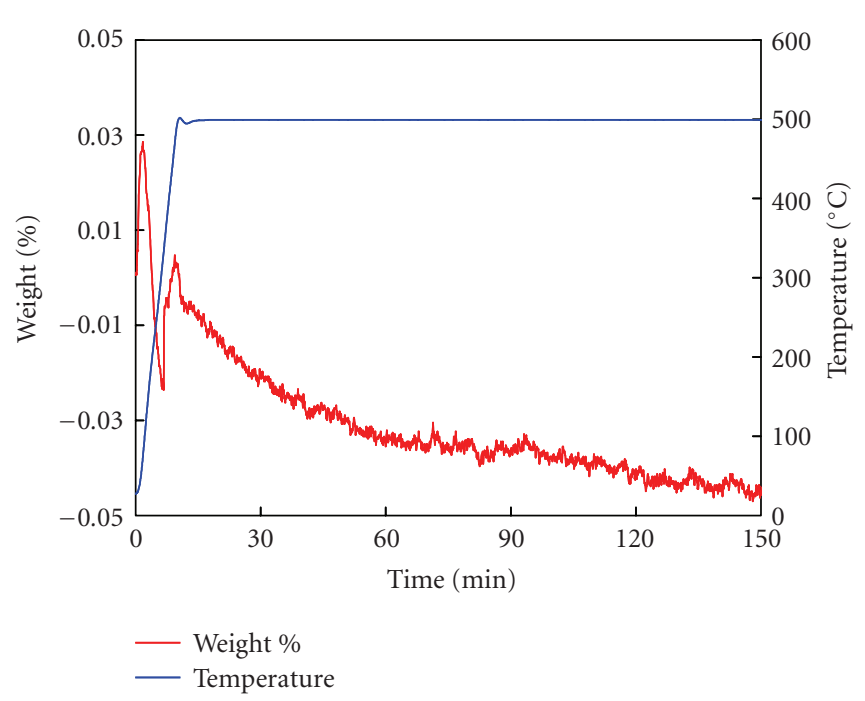

(b)

FIgURE 7: TGA results of the oxidation process from (a) $\mathrm{Cu}_{2} \mathrm{O}$ thin layer (initial mass: $49.598 \mathrm{mg}$ ) and (b) $\mathrm{CuO}$ thin layer (initial mass: $38.061 \mathrm{mg})$.

density were those that tarnished black. And the light to dark grey samples with 10 to $20 \% \mathrm{O}_{2}$ partial pressures correspond to the low to medium NW density. Since bulk $\mathrm{CuO}$ is known to be grey to black in color and $\mathrm{Cu}_{2} \mathrm{O}$ is red, it can be roughly inferred that the oxide surface and possibly the NWs are CuO. However, in many cases the color of nanostructures is very different from that of their corresponding bulk structures due to morphology-induced interference and scattering. Thus, the observed color can only be used as a rough guide and the actual composition of the surface and the NWs must be obtained with the aid of advanced characterization techniques. A UV-Visible absorption spectrum of a high-density NW array similar to the sample shown in Figure 2(d) is presented in Figure 3. The band gap of the as-grown NWs was estimated from the absorption spectrum by fitting a tangential line passing the midpoint of the first absorption edge (750-940 nm) and reading out the $x$-intercept. In this way, a band gap of approximately $1.2 \mathrm{eV}$ $(1030 \mathrm{~nm})$ corresponding to bulk $\mathrm{CuO}$ can be extracted.

To further analyze the oxide layering structure, an oxide flake was carefully removed from a copper substrate oxidized in pure $\mathrm{O}_{2}$. The SEM image of the flake is shown 


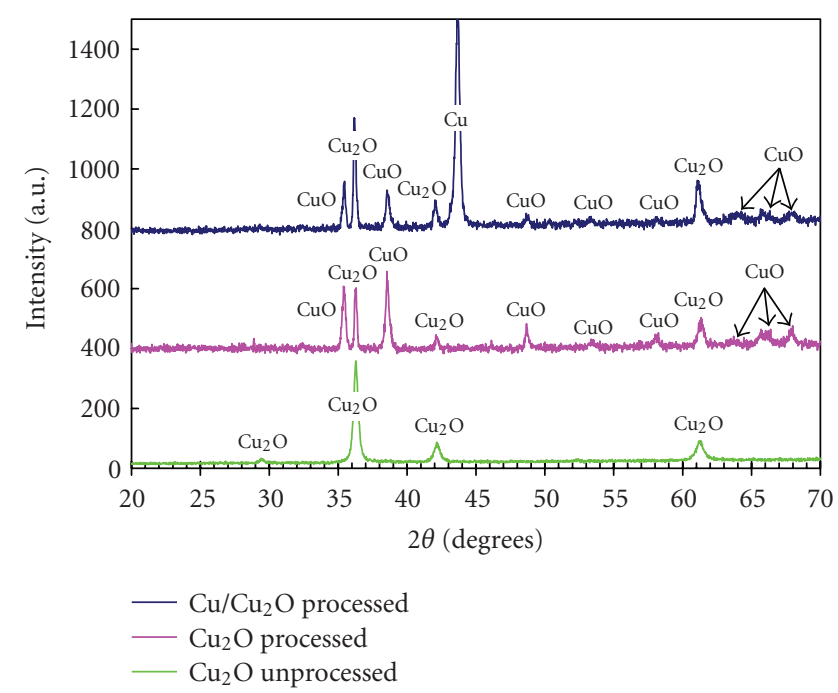

(a)

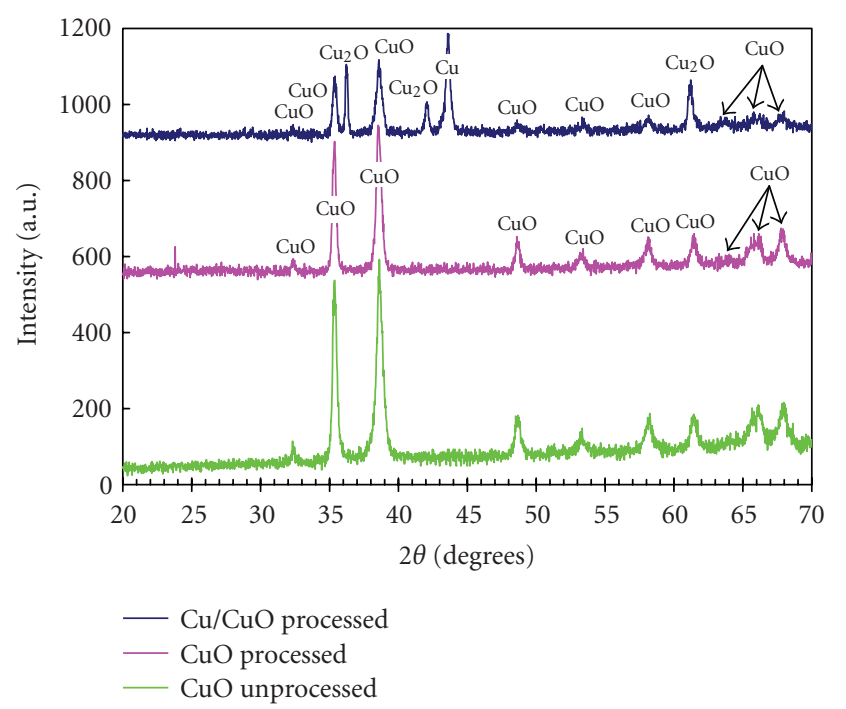

(b)

Figure 8: XRD spectra of the substrates involving $\mathrm{Cu}_{2} \mathrm{O}(\mathrm{a})$ and $\mathrm{CuO}(\mathrm{b})$.

in Figure 4(a), with an amplified figure shown in the inset. Three layers can be distinguished: a bottom layer that lies directly above the copper substrate, an intermediate layer that the NWs grow from, and a top NW layer. The XRD spectrum of an oxidized $\mathrm{Cu}$ substrate is shown in Figure 4(b), which indicates the presence of both $\mathrm{Cu}_{2} \mathrm{O}$ and $\mathrm{CuO}$. However, no information on the individual layer composition can be extracted. The theoretical layering composition (labeled in Figure 4(a)) has been discussed in $[8,9]$ with $\mathrm{CuO}$ as the NWs and the intermediate layer and $\mathrm{Cu}_{2} \mathrm{O}$ as the bottom layer. The theoretical hypothesis on the NWs has been proved by our experiments.

To confirm the rest of the layering composition, EDX spectra were obtained from the top and the bottom surfaces of an oxide flake similar to that shown in Figure 4. In addition, EDX standards were produced from compacted $\mathrm{CuO}$ $(3 \mathrm{Ns})$ and $\mathrm{Cu}_{2} \mathrm{O}(2 \mathrm{Ns})$ powders. The resulting spectra and region analysis are presented in Figure 5. The spectra were made up of $\sim 100000$ counts, taken at identical parameters of $5 \mathrm{keV}$ and $10000 \times$ magnification with a 60 degree sample tilt. Regions of $0.400-0.600 \mathrm{keV}$ and $0.620-1.080 \mathrm{keV}$ were created about the $\mathrm{OK} \alpha$ and $\mathrm{CuL} \alpha$ peaks, respectively, and the number and the percentage of gross counts in each region was determined. The relatively small fraction of oxygen counts detected is due to the low energy X-rays produced and the subsequent reabsorption upon exiting the sample material. The results indicate that the percent of gross counts for oxygen and copper taken from the bottom of the flake matched that of the standard $\mathrm{Cu}_{2} \mathrm{O}$. Likewise, the percent of gross counts for oxygen and copper taken from the top of the flake matched that of the standard $\mathrm{CuO}$. Furthermore, a simple calibration has been carried out to correlate the gross count ratio of oxygen to copper with the molar ratio of $\mathrm{O}$ to $\mathrm{Cu}$ (or $x$ value of $\mathrm{CuO}_{x}$, where $x$ equals $0,0.5$ and 1 for $\mathrm{Cu}$, $\mathrm{Cu}_{2} \mathrm{O}$, and $\mathrm{CuO}$, resp.) in standard reference samples. The resulting $x$ value is 0.99 for the top layer and 0.48 for the bot- tom layer in our sample. Our experimental results indicate distinct oxide layers and directly agree with the theoretical speculation $[8,9]$ of the bottom layer of $\mathrm{Cu}_{2} \mathrm{O}$ and the intermediate layer of $\mathrm{CuO}$. The layering structures can be used to interpret the $\mathrm{CuO} \mathrm{NW}$ growth mechanism as elaborated in [6]: $\mathrm{Cu}_{2} \mathrm{O}$ acts as a precursor for the second oxidation step to $\mathrm{CuO}$ where the slow production rate of $\mathrm{CuO}$ results in a localized $\mathrm{CuO}$ vapor pressure and a continuous growth mode for $\mathrm{CuO}$ NWs by means of the vapor-solid growth mechanism.

Compacted $\mathrm{CuO}$ and $\mathrm{Cu}_{2} \mathrm{O}$ layers with and without the $\mathrm{Cu}$ foil support were also used to grow $\mathrm{CuO}$ NWs in pure $\mathrm{O}_{2}$ at $500^{\circ} \mathrm{C}$ for 150 minutes. The SEM images of the oxidized substrates are presented in Figure 6. High-density NW growth on the $\mathrm{Cu} / \mathrm{Cu}_{2} \mathrm{O}$ substrate, medium NW growth on the $\mathrm{Cu} / \mathrm{CuO}$ substrate, low NW growth on the $\mathrm{Cu}_{2} \mathrm{O}$ substrate, and no NW growth on the $\mathrm{CuO}$ substrate have been observed. The results indicate the importance of $\mathrm{Cu}_{2} \mathrm{O}$ to $\mathrm{CuO}$ conversion for the growth of $\mathrm{CuO}$ NWs as well as the presence of a Cu substrate for high-density NW growth. The importance of the $\mathrm{Cu}$ substrate is possibly in its role as a $\mathrm{Cu}$ ion source and in establishing a chemical potential gradient for the diffusion of $\mathrm{Cu}$ ions to the substrate surface. In Figure 6(a), the relatively thick compacted $\mathrm{Cu}_{2} \mathrm{O}$ layer with high-density NWs at its surface is seen at the top side of the $\mathrm{Cu}$ substrate and the familiar layering scheme is observed at the bottom of the substrate. Also note that the oxide layers of Figures 6(a)-6(c) are uniformly structured with less or without pores, whereas the presumably unchanged $\mathrm{CuO}$ sample in Figure 6(d) has a porous structure consistent with compacted powders.

To determine if the oxidation took place, the $\mathrm{Cu}_{2} \mathrm{O}$ and $\mathrm{CuO}$ thin layers were processed separately in a TGA. From the TGA results shown in Figure 7, it is clear that the $\mathrm{Cu}_{2} \mathrm{O}$ thin layer oxidized whereas the $\mathrm{CuO}$ thin layer did not. The small decrease in the weight for the $\mathrm{CuO}$ thin layer is 
a consequence of the thermal expansion of the TGA and can be ignored. XRD spectra were also obtained from each sample and compared to those of unprocessed $\mathrm{Cu}_{2} \mathrm{O}$ and $\mathrm{CuO}$ in Figure 8. For those samples which oxidized to form $\mathrm{CuO}$ NWs $\left(\mathrm{Cu}_{2} \mathrm{O}, \mathrm{Cu} / \mathrm{Cu}_{2} \mathrm{O}, \mathrm{Cu} / \mathrm{CuO}\right)$, the XRD spectra indicate the presence of both $\mathrm{CuO}$ and $\mathrm{Cu}_{2} \mathrm{O}$, suggesting the importance of the oxide layering on NW growth.

\section{CONCLUSION}

$\mathrm{CuO}$ NWs have been successfully grown from both copper and copper-containing substrates through direct oxidation of the substrates in oxidative environments. The as-grown NWs have a band gap of $\sim 1.2 \mathrm{eV}(1030 \mathrm{~nm})$ corresponding to bulk $\mathrm{CuO}$. Oxygen partial pressure was found to significantly affect NW growth. The vertical alignment of the $\mathrm{NW}$ increases with increasing $\mathrm{O}_{2}$ partial pressures, while the average length and diameter of the NWs seem to decrease with decreasing $\mathrm{O}_{2}$ partial pressures. Analyses on the oxidized substrates indicate $\mathrm{CuO}$ as the NWs and the intermediate layer and $\mathrm{Cu}_{2} \mathrm{O}$ as the bottom layer. The oxidation of compacted $\mathrm{CuO}$ and $\mathrm{Cu}_{2} \mathrm{O}$ layers with and without $\mathrm{Cu}$ substrate suggests the importance of $\mathrm{Cu}_{2} \mathrm{O}$ to $\mathrm{CuO}$ conversion for the growth of $\mathrm{CuO}$ NWs, as well as the importance of a $\mathrm{Cu}$ substrate for high-density NW growth.

\section{ACKNOWLEDGMENTS}

This work was supported by National Science Foundation (DMI-0609059), WiSys Technology Foundation, as well as the University of Wisconsin-Milwaukee (UWM) Advanced Analysis Facility (AAF) Summer Internship Program. The authors thank Steven Hardcastle for assistance with SEM, EDX, and XRD analyses, which were carried out at the AAF of UWM. TEM analyses were performed at the UWM HRTEM Laboratory. The authors also thank the anonymous reviewers for their valuable comments and suggestions.

\section{REFERENCES}

[1] Y. Li, F. Qian, J. Xiang, and C. M. Lieber, "Nanowire electronic and optoelectronic devices," Materials Today, vol. 9, no. 10, pp. 18-27, 2006.

[2] F. Patolsky, G. F. Zheng, and C. M. Lieber, "Nanowire-based biosensors," Analytical Chemistry, vol. 78, no. 13, pp. 42604269, 2006.

[3] C. Wang, X. Q. Fu, X. Y. Xue, Y. G. Wang, and T. H. Wang, "Surface accumulation conduction controlled sensing characteristic of p-type $\mathrm{CuO}$ nanorods induced by oxygen adsorption," Nanotechnology, vol. 18, no. 14, Article ID 145506, 5 pages, 2007.

[4] R. S. Wagner and W. C. Ellis, "Vapor-liquid-solid mechanism of single crystal growth," Applied Physics Letters, vol. 4, no. 5, pp. 89-90, 1964.

[5] G.-C. Yi, C. Wang, and W. I. Park, "ZnO nanorods: synthesis, characterization and applications," Semiconductor Science and Technology, vol. 20, no. 4, pp. S22-S34, 2005.

[6] X. Jiang, T. Herricks, and Y. N. Xia, "CuO nanowires can be synthesized by heating copper substrates in air," Nano Letters, vol. 2, no. 12, pp. 1333-1338, 2002.
[7] S. Anandan, X. Wen, and S. Yang, "Room temperature growth of $\mathrm{CuO}$ nanorod arrays on copper and their application as a cathode in dye-sensitized solar cells," Materials Chemistry and Physics, vol. 93, no. 1, pp. 35-40, 2005.

[8] H. Wu, D. Lin, and W. Pan, "Fabrication, assembly, and electrical characterization of CuO nanofibers," Applied Physics Letters, vol. 89, no. 13, Article ID 133125, 2006.

[9] K. Hauffe, Oxidation of Metals, Plenum Press, New York, NY, USA, 1965.

[10] K.-H. Muller, High-Tc Superconductors and Related Materials, vol. 86, Kluwer Academic, Dordrecht, The Netherlands, 2001.

[11] O. A. Chaltykyan, Copper-Catalytic Reactions, Consultants Bureau, New York, NY, USA, 1966.

[12] P. A. Cox, Transition Metal Oxides: An Introduction to Their Electronic Structure and Properties, Oxford University Press, New York, NY, USA, 1992.

[13] S.-C. Yeon, W.-Y. Sung, W.-J. Kim, S.-M. Lee, H.-Y. Lee, and Y.-H. Kim, "Field emission characteristics of $\mathrm{CuO}$ nanowires grown on brown-oxide-coated $\mathrm{Cu}$ films on $\mathrm{Si}$ substrates by conductive heating in air," Journal of Vacuum Science \& Technology B, vol. 24, no. 2, pp. 940-944, 2006.

[14] Y. W. Zhu, T. Yu, F. C. Cheong, et al., "Large-scale synthesis and field emission properties of vertically oriented $\mathrm{CuO}$ nanowire films," Nanotechnology, vol. 16, no. 1, pp. 88-92, 2005.

[15] C. H. Xu, C. H. Woo, and S. Q. Shi, "The effects of oxidative environments on the synthesis of $\mathrm{CuO}$ nanowires on $\mathrm{Cu}$ substrates," Superlattices and Microstructures, vol. 36, no. 1-3, pp. 31-38, 2004.

[16] R. Haugsrud, "The influence of water vapor on the oxidation of copper at intermediate temperatures," Journal of the Electrochemical Society, vol. 149, no. 1, pp. B14-B21, 2002.

[17] C.-T. Hsieh, J.-M. Chen, H.-H. Lin, and H.-C. Shih, "Synthesis of well-ordered $\mathrm{CuO}$ nanofibers by a self-catalytic growth mechanism," Applied Physics Letters, vol. 82, no. 19, pp. 33163318, 2003.

[18] M. Mattila, T. Hakkarainen, H. Jiang, E. I. Kauppinen, and H. Lipsanen, "Effect of substrate orientation on the catalyst-free growth of InP nanowires," Nanotechnology, vol. 18, no. 15, Article ID 155301, 5 pages, 2007.

[19] T. G. Woodcock, J. S. Abell, J. Eickemeyer, and B. Holzapfel, "Crystal orientation mapping of $\mathrm{NiO}$ grown on cube textured Ni tapes," Journal of Microscopy, vol. 216, no. 2, pp. 123-130, 2004. 

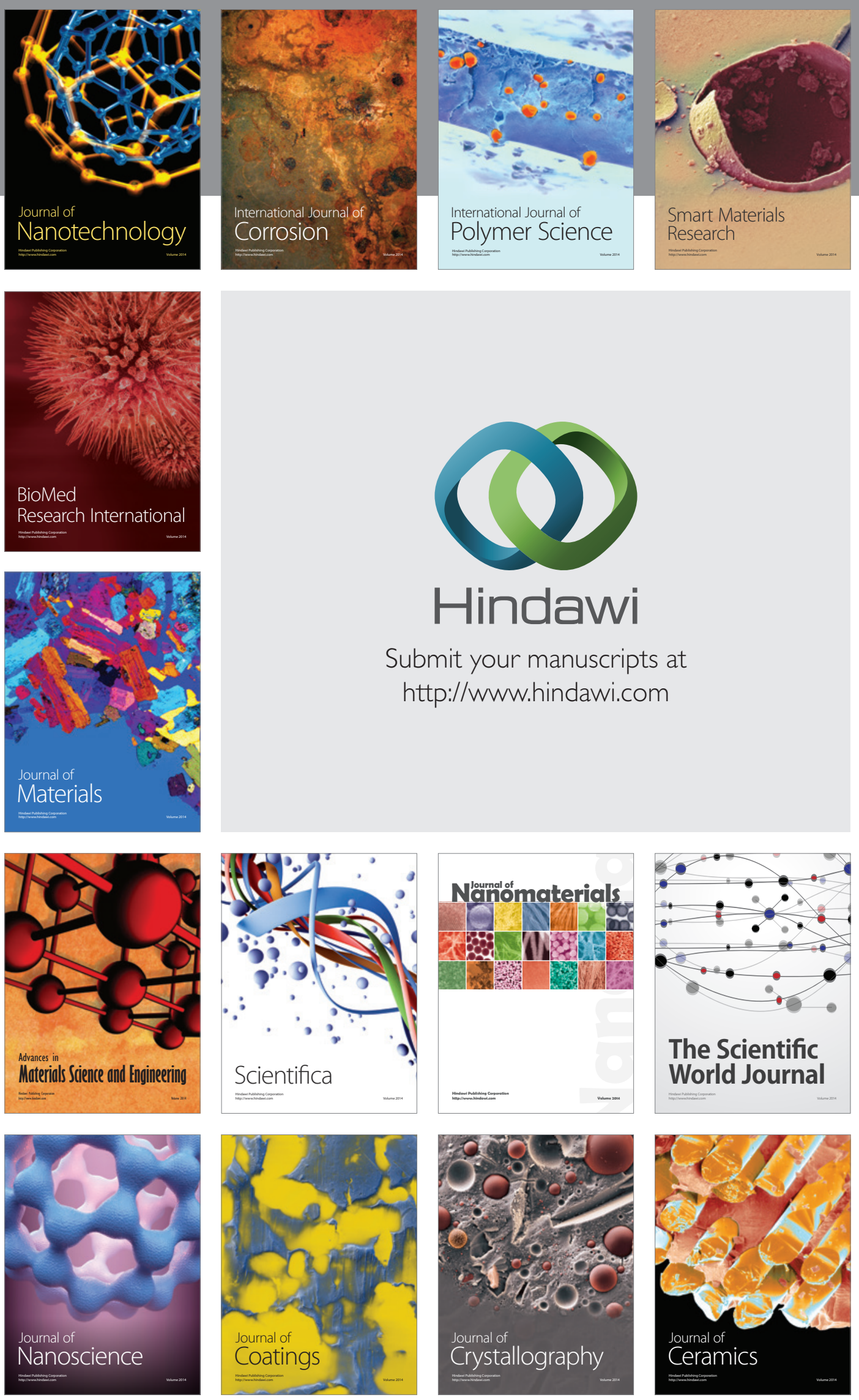

The Scientific World Journal

Submit your manuscripts at

http://www.hindawi.com

\section{World Journal}

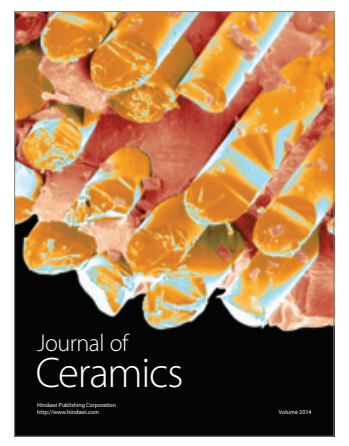

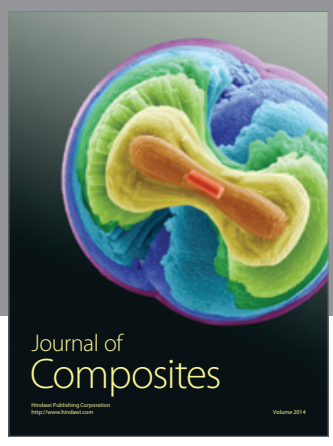
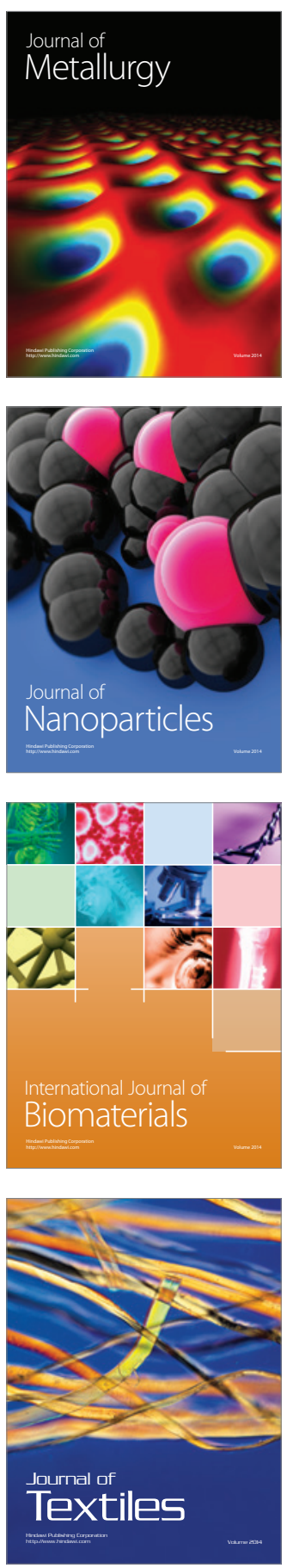